\title{
Simulation analysis of resource flexibility on healthcare processes
}

This article was published in the following Dove Press journal:

Journal of Multidisciplinary Healthcare

13 October 2016

Number of times this article has been viewed

\section{Yusta W Simwita \\ Berit I Helgheim}

Department of Logistics, Molde University College, Molde, Norway
Correspondence: Yusta W Simwita

Department of Logistics, Molde

University College, Britvegen 2, 6410

Molde, Norway

Tel +47 7II95785

Emailsimwita2009@gmail.com
Purpose: This paper uses discrete event simulation to explore the best resource flexibility scenario and examine the effect of implementing resource flexibility on different stages of patient treatment process. Specifically we investigate the effect of resource flexibility on patient waiting time and throughput in an orthopedic care process. We further seek to explore on how implementation of resource flexibility on patient treatment processes affects patient access to healthcare services. We focus on two resources, namely, orthopedic surgeon and operating room. Methods: The observational approach was used to collect process data. The developed model was validated by comparing the simulation output with actual patient data collected from the studied orthopedic care process. We developed different scenarios to identify the best resource flexibility scenario and explore the effect of resource flexibility on patient waiting time, throughput, and future changes in demand. The developed scenarios focused on creating flexibility on service capacity of this care process by altering the amount of additional human resource capacity at different stages of patient care process and extending the use of operating room capacity.

Results: The study found that resource flexibility can improve responsiveness to patient demand in the treatment process. Testing different scenarios showed that the introduction of resource flexibility reduces patient waiting time and improves throughput. The simulation results show that patient access to health services can be improved by implementing resource flexibility at different stages of the patient treatment process.

Conclusion: This study contributes to the current health care literature by explaining how implementing resource flexibility at different stages of patient care processes can improve ability to respond to increasing patients demands. This study was limited to a single patient process; studies focusing on additional processes are recommended.

Keywords: agile strategy, waiting time, throughput, patient access, responsiveness

\section{Introduction}

Over the last twenty years healthcare industry has experienced significant changes, with patient demands changing at an ever increasing speed. ${ }^{1-3}$ These changes require greater flexibility at different stages of patient care processes, which can increase the ability to respond quickly to changes in patient demands and needs. ${ }^{4-7}$ A new process improvement technique - agile, has been proposed as a key strategy that can be used to improve healthcare processes. ${ }^{8}$ Flexibility is a key characteristic of the agile strategy and is needed in order to achieve prompt responses to rapidly changing demands and requirements from patients. Flexibility in patient care processes enhances care providers to handle unique patient demands and needs. ${ }^{5,9}$ 
Despite the fact that the agile strategy has been proposed as a strategy for improving health care processes, its adoption in this field is still at an embryonic stage. Little empirical research exists in the health care literature exploring the effect of agile strategy on healthcare processes. In general agile has been widely studied as a company-wide strategy leading to limited research of agility at a process level. ${ }^{5,8,10,11}$ Also, most existing studies focus on creating flexibility on a single resource such as human resource or facility resource (eg, operating room), thus lacking a holistic view of the process. ${ }^{4,12,13}$ In order to facilitate increased patient response for the entire care process, from when patient arrives to the point of discharge, flexibility on both human resource and facility resource is vital. ${ }^{12}$ This study aims to fill part of this gap by exploring the effect of creating flexibility on service capacity of this care process by focusing on two critical resources, namely, orthopedic surgeons and operating room capacity.

This objective will be accomplished by using discreteevent simulation to explore the improvements that can be achieved by deploying resource flexibility on different stages of patient treatment processes. The specific objective of this paper is two-fold: first, to explore the best resource flexibility scenario and to investigate the effects of implementing resource flexibility on patient waiting time and throughput and, second, to explore how implementation of resource flexibility on different stages of patient treatment processes affects patient access to health care services. To achieve this objective, the following question will be addressed: how is process outcome affected by resource flexibility? Here, process outcome is described in terms of process performance measures: patient throughput and waiting time.

The rest of this paper is organized as follows: the second section presents a literature review while the third section presents material and methods. The fourth section presents the simulation results from the scenario testing and modeling. The fifth section presents a discussion of the simulation results, followed by the conclusion section.

\section{Literature review}

The origin of the agile strategy can be traced back to the agility forum of a group of scholars at Iacocca Institute, Lehigh University, in $1991 .{ }^{14}$ Agility was introduced as the response to increasing business turbulence and uncertainties. ${ }^{15}$ Agility is a multidimensional concept, hence several definitions have been offered since its conception. However all the definitions still remain within the same theme of increasing responsiveness and flexibility to increasing uncertain customer demands. ${ }^{16}$ In this paper agile is defined as the ability of being customer responsive and mastering increasing demand changes. ${ }^{17}$
The key objective of agile strategy is to enhance flexibility in care processes in order to respond to the needs of increasingly demanding patients. ${ }^{5}$ Working with flexible capacity is the key component of an agile strategy to enhance reduced throughput time and increased response speed. Flexible capacity requires high availability of extra personnel or other resources required to perform processes in a timely manner, regardless of the volume of real demand. The main advantage of this approach is that adjacent steps in the process receive reliable deliveries, ie, on-time deliveries. This reduces throughput time and increases access to services. ${ }^{2,5}$

In this paper, resource flexibility is defined as "the ability to dynamically reallocate units of resource from one stage of production process to another in response to shifting bottlenecks". ${ }^{4}$ To supplement this definition, literature points out that resource flexibility can further be created by the ability to alter amount of resource or ability to extend the use of a resource. ${ }^{7}$ Drawing from this description, resource flexibility in this study is created through altering amount of resource capacity or extending the use of resource capacity at different stages of patient care process. When each unit of a resource can be allocated to any stage of the production process, it leads to substantial improvements in operational performance. The literature further asserts that resource flexibility positively and significantly contributes to agile process improvements. ${ }^{4,18}$

Despite the fact that the agile strategy has received the attention of many health care scholars, limited empirical research has been conducted to explore the possibility of applying this strategy in health care. ${ }^{10}$ Aronsson et $\mathrm{al}^{5}$ conducted a study in a Swedish health care setting to explore the link between the agile strategy and health care supply chain performance. By focusing on how lean and agile can be used as process strategies, they pointed out that the key requirement in health care today is about organizing for quick response and flexibility at the system level. Olsson and Aronsson ${ }^{7}$ conducted a study in a Swedish hospital to identify strategies for different actions used in patient treatment. They noted that the hospital's agile actions were reactive and lacking in proactive measures. They found very few actions that directly managed external variation. In the current study, agile is used as a process improvement strategy whereby the main objective is to explore entire patient treatment process and to examine the effect of resource flexibility in different stages of patient treatment process. This study will focus on creating flexibility on the service capacity of this care process by altering the amount of human resource capacity at different stages of care process and extending the use of operating room capacity. 


\section{Simulation in health care processes}

Due to the complexity and uncertainty of the health care process, simulation has become the most important tool in analyzing and evaluating the responses of systems under various scenarios. It has proven its viability and capability as a powerful technique and method in exploring resource-driven processes ${ }^{19-21}$ This has led to a number of simulation studies on care processes.

Weerawat et $\mathrm{al}^{22}$ deployed discrete-event simulation to estimate the capability and service level of an orthopedic outpatient clinic. They found that allocating the availability of critical resources over an extended time span by employing a flexible work schedule on the basis of patient demand can increase system efficiency. They developed a strategy that can be used to match patient demand with resources. Rau et al ${ }^{23}$ constructed a discrete-event simulation model to explore the bottlenecks of the operations in the physical therapy room. They further discussed the impact of pooling resources on clinic efficiency, which they noted increases flexibility in critical resource schedules. Baril et a ${ }^{24}$ studied the relationships and interactions between patient flows, resource capacities, and appointment scheduling rules in order to improve an outpatient orthopedic clinic. They found that to achieve this, the clinic's performance, resources, and appointment scheduling rules must be applied to different patient flows. Duguay and Chetouane ${ }^{25}$ deployed discrete-event simulation in an emergency department to reduce patient waiting times and to improve service delivery and throughput. They developed a linkage between patient waiting time and resource availability, and found that matching critical resources with patient demand reduces patient waiting time.

This paper focuses on using discrete event simulation to explore orthopedic care process and propose resource flexibility scenarios that can be used to reduce patient waiting time and improve patient throughput. Further discrete event simulation will be used to explore how the best scenario can accommodate future increasing demand.

\section{Material and methods}

\section{Bugando Orthopedic Clinic as empirical evidence}

The Bugando Medical Centre (BMC) is one of the four teaching and consultant hospitals in Tanzania. It serves primarily the Lake and Western zones of the United Republic of Tanzania. The BMC is situated along the shores of Lake Victoria in Mwanza City. This 900-bed hospital has approximately 1,000 employees. The BMC is a referral center for tertiary specialist care serving eight regions: Mwanza, Tabora, Kigoma,
Kagera, Mara, Geita, Simiyu, and Shinyanga. In general, this hospital serves a population of approximately 13 million.

Globally road traffic injuries are a growing concern that put much pressure on healthcare providers on how to meet increasing surgical demand. ${ }^{26}$ This is the same challenge experienced by the Bugando orthopedic department. It is faced with increasing surgical demand for orthopedic services. This is to a large extent associated by the increase of road traffic injuries, frequently caused by motorcyclists across the region and Tanzania as a whole. One recent study at this hospital reported that road traffic injuries contributed up to $68.5 \%$ of orthopedic cases. This trend is expected to continue unless critical measures are taken. ${ }^{27}$ The increasing demand has led to high crowding and excessive waiting times and lists for orthopedic patients visiting this department. Existing surgeons and operating room capacity are the main constraints in this care process. Creating flexibility in these critical resources is of paramount importance in order to increase patient access to care at this clinic.

\section{Orthopedic department resources}

The hospital under study has four specialized orthopedic surgeons and five operating theatres that serve the entire hospital community of 13 million people. The orthopedic department has only been allocated two operating rooms out of the existing five. Two orthopedic surgeons per day perform operations on Mondays, Wednesdays, and Fridays The total capacity for the three allocated days in the operating theatre is equivalent to six rooms per week. At the clinic, two orthopedic surgeons per day attend to patients on Tuesdays and Wednesdays. Other resources at the clinic include three nurses who take patients to surgeons for examination. Bugando Hospital also has a central laboratory and an X-ray section, which serve the entire hospital community.

\section{Describing clinical operations}

As part of the process exploration, and before mapping this process, we held interviews with hospital management teams, surgeons, and heads of departments related to orthopedic care (laboratory, X-ray, registrations, and the orthopedic ward). Model credibility and validity was ensured by involving key surgeons at the orthopedic clinic and the head of the operating rooms during the conceptual model development. Further insight into the orthopedic care process was obtained by holding discussions with nurses and patients at the clinic. The entire orthopedic care process is described below.

Upon arrival at the hospital, patients register with the registration department. They usually arrive at the 


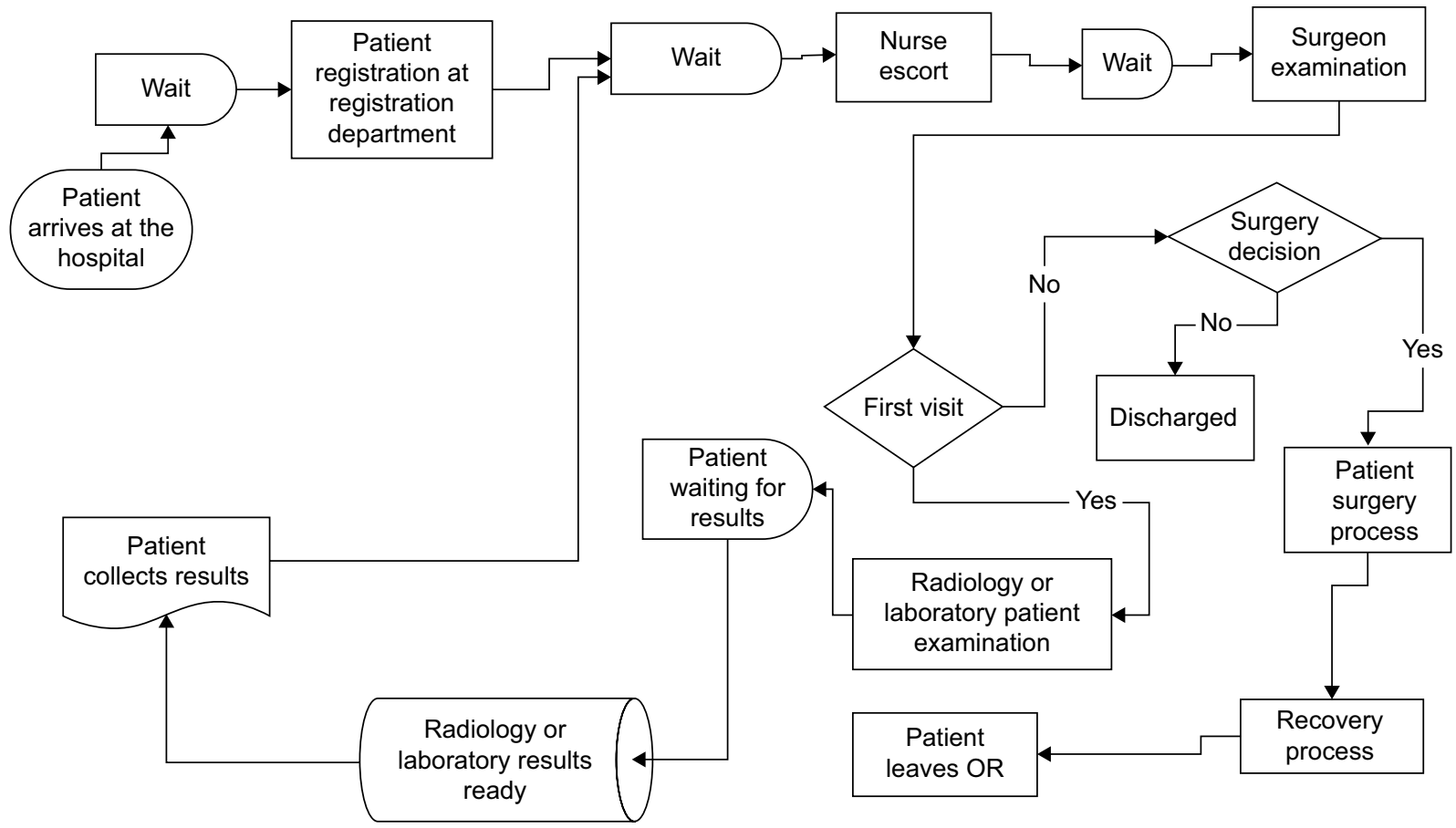

Figure I Current process in the orthopedic department.

Abbreviation: OR, operating room.

registration department from approximately 6 am even though registration starts at 7 am and clinical services start at $8 \mathrm{am}$. Consequently, most patients arrive at the clinic before the start of clinical services and must wait for the start of the clinical session, including the arrival of surgeons. Even though there is no clear reason as to why some patients tend to arrive before the start of registration and clinical services, it is most likely due to the high number of patients attending registration and clinic per day. Thus, some patients would like to arrive early so that they can be among the first patients in the registration and treatment queues. Surgeons occasionally delay their arrival at the clinic by $15-45$ minutes after the clinic has opened because of other tasks/obligations in the hospital. When surgeons arrive, examination services begin, and patients are escorted by nurses to the examination rooms. During the first examinations, surgeons normally order ancillary tests such as X-ray or laboratory tests. Patients requiring the ordered tests will then undergo their respective tests, which can be X-ray or laboratory tests. When ancillary test results are ready, patients take their results back to the nurse, who then takes the results to the surgeon for further diagnosis. After a second examination, a patient is either discharged or transferred for surgery. Conceptual model of the studied orthopedic care process that was translated into the computer simulation model (Figure 1).
Table I Simulation model input based on current orthopedic care process (minutes)

\begin{tabular}{|c|c|c|}
\hline Process & Distribution (minutes) & Resources \\
\hline Patient arrivals & $0.5+\operatorname{EXPO}\left(2.62^{\mathrm{a}}\right)$ & \\
\hline Registration & $5.5+$ GAMM $(1.97,4.73)$ & Clerks \\
\hline Nurse escort & I.5+ WEIB $(3.59$, I.49) & Nurse \\
\hline First examination & $3.5+$ WEIB $(15.4,1.74)$ & Surgeons \\
\hline $\begin{array}{l}\text { Second } \\
\text { examination }\end{array}$ & $3.5+\operatorname{ERLA}(2.66,4)$ & Surgeons \\
\hline X-ray & I3.5+ WEIB $(3.79,2.15)$ & X-ray technician \\
\hline Laboratory & $\operatorname{NORM}(25.4,2.98)$ & Laboratory technician \\
\hline Surgery & $10+\operatorname{GAMM}(46.9,1.34)$ & Surgeons \\
\hline Recovery & $4.5+14 \times \operatorname{BETA}(2.42,1.65)$ & $\begin{array}{l}\text { Operating room } \\
\text { personnel }\end{array}$ \\
\hline
\end{tabular}

Note: a Mean.

Abbreviations: EXPO, exponential; GAMM, gamma; WEIB, Weibull; ERLA, Erlang; NORM, normal.

\section{Data collection and analysis}

This study was approved by the Research and Ethics committee of the Catholic University of Health and Allied Sciences and Bugando Medical Centre. Patient written consent was not considered necessary by the committee as this was a process improvement study and no medical or personal information was taken from the patients. Data collection was anonymous. This study is based on the interviews and observational data from the orthopedic clinic from June 2012 to August 2012. We followed patient from arrival at the registration department 
to the point of discharge. For data collection process we used stopwatches and structured data sheets whereby each column represented either waiting or assessment time of the observed patient activity. The time recorded includes waiting time and service time during registration, examination at the clinic by the surgeon, the surgical process, recovery, X-rays, and laboratory tests. Based on the observations, an average of 35 patients attend the clinic per day, of which $20 \%$ undergo the entire process up to surgery, while $80 \%$ are discharged. During the data collection period, 178 patients underwent the entire process from arrival, to surgery, to discharge.

We followed all necessary steps to perform the analysis of the collected data for distribution fitting. We used scatter plots and linear correlation techniques to assess data independence. Furthermore, we used summary statistics, histograms, and box plot techniques to hypothesize the families of distribution. After identifying the distribution, we used a chi square test to determine the representativeness of the fitted distribution. ${ }^{28}$ Thus, chi square tests for goodness-of-fit led to the selection of the final distribution. Discrete event simulation was used as the main methodology for this study. Additionally the model was developed using Arena (Version 13.0). We used the Arena input analyzer to generate the parameters of the selected distribution, which were used in the simulation model. Table 1 shows the selected distribution.

\section{Model development and assumptions}

It is impossible to replicate complex health care delivery systems that involve human behavior and decisions in a simulation model. ${ }^{29}$ Thus, we made a number of assumptions that guided simulation model development. First, our study considers the operational system only between 6 am and $4 \mathrm{pm}$ because patients begin to arrive from $6 \mathrm{am}$. Second, the main objective of this study is to explore the entire patient treatment process, thus it focused on patients who underwent the entire process from arrival to discharge after surgery. Third, based on the second assumption, decisions on whether surgery is needed are made only after the second examination (ie, after surgeons receive the ordered X-ray and laboratory test results). Fourth, resources are available to orthopedic patients for the two clinical and three allocated surgical days. Fifth, this study assumes that the second examination queue has priority over the first examination queue. The model limitations were based on the following grounds: transfer times (transport times) within the orthopedic department were not taken into consideration because the main focus of this study was the orthopedic department, particularly the interaction between specialist surgeons and patients.
The simulation model was then developed within the aforementioned assumptions and ran for 100 independent replications and the system was reinitialized between replication. In this model each replication stands for a single day of orthopedic care delivery at this clinic. The normal operation of the studied clinic is from 8 am to $4 \mathrm{pm}$, however, we simulated the model for 9 hours because during the data collection process the clinic usually closed at $5 \mathrm{pm}$. Patients in this care process are examined based on first-in, first-out service discipline. Likewise, in the simulation model patients were also served using the same first-in, first-out queuing discipline. Patient arrivals were generated based on the observed schedule of the two allocated clinic days. Also, in the surgical room, the model simulates based on the schedule of the observed three allocated surgical days.

\section{Model verification and validation}

Model verification is a key step used to ensure that the conceptual model is well reflected in the simulation and the model is running free of errors. ${ }^{30}$ To meet this requirement we verified simulation model using Arena debugging tools and animation, and the model was running correctly. We took the following measures to validate the model: firstly, we maintained high face validity of the model by involving key orthopedic specialist surgeons and the head of the operating theatre in the model's development. The head of the operating room was also involved in the data collection process inside the operating room. Further, two performance measures were used for validation: patient waiting time at the clinic and patient throughput per day in the surgical room. Throughput was measured as the number of patients undergoing surgery per day. The average patient waiting time for a surgeon at the clinic was 2.8 hours, at a $95 \%$ confidence interval. This is not very different from the observed patient waiting time for a surgeon: 2.4 hours. The average throughput based on observation was 7.3 while the average throughput based on the simulation, with a $95 \%$ confidence interval, was 5 . To increase model validation we run the simulation model using the actual patients arrivals instead of sampling from a selected exponential distribution, and the same results were obtained.

The major difference between simulation output and observed data was found on waiting time for second examination at the clinic. The average waiting time from the simulation model is 0.14 hours while based on the real data the average waiting time is 0.8 hours. This is probably because in the simulation model second visit patients were given priority over the first examination patients. Thus, in the model, 
Table 2 Scenarios and their corresponding resource changes

\begin{tabular}{llll}
\hline & $\begin{array}{l}\text { Additional } \\
\text { staff at the } \\
\text { clinic }\end{array}$ & $\begin{array}{l}\text { Additional } \\
\text { staff in the } \\
\text { operating } \\
\text { room }\end{array}$ & $\begin{array}{l}\text { Extended use of the } \\
\text { operating room by one } \\
\text { hour and a 10\% increase } \\
\text { in daily surgeries }\end{array}$ \\
\hline Scenario I & $\mathrm{I}$ & 0 & $\mathrm{I}$ \\
Scenario 2 & 0 & $\mathrm{I}$ & $\mathrm{I}$ \\
Scenario 3 & $\mathrm{I}$ & $\mathrm{I}$ & $\mathrm{I}$ \\
Scenario 4 & $\mathrm{I}$ & 2 & $\mathrm{I}$ \\
Scenario 5 & 2 & $\mathrm{I}$ & $\mathrm{I}$ \\
\hline
\end{tabular}

patients bringing their ancillary results for second examination were always given first priority in the queue over the first examination patients. Normally, patients with an ancillary test coming for second examination are always preceded by other patients in the queue. Despite this discrepancy the model is considered valid because other performance measures such as first waiting time, throughput, and surgeons utilization are close to the actual collected data.

\section{Proposed resource flexibility scenario}

As stated previously, this department is facing increasing surgical demand which is accompanied by constraint on surgeons and operating room capacity. Thus, our proposal aimed at exploring the entire orthopedic care process from when patient arrives to the point of discharge, and proposing the resource flexibility scenario that can be used to increase the speed of responding to the current growing patient demand at this clinic. Based on the observation of this process during data collection, we suggest implementation of resource flexibility by changing the care procedure from using not only specialist surgeons at the clinic and surgical room but also utilizing mid-level health workers or nonclinician physicians. ${ }^{31,32}$ These resources are cross-trained to increase care capacity and usually perform multiple tasks, including internal medicine, minor surgery, gynecology, and obstetrics. ${ }^{33}$ They may be assigned to more routine parts of the orthopedic process in order to take care of simple treatments such as closing and cleaning wounds or minor surgery. This care procedure will increase flexibility in orthopedic care process since simple cases will be dedicated to mid-level health workers. This will release capacity to surgeons to deal with complex cases. Using mid-level health workers for routine and simple cases and surgeons for more complex cases will increase the speed of response to the increasing patient demands. This will lead to reductions in patient delays and increased access to health services.

We propose that flexibility can be achieved by reallocating these units of resources from one stage of the orthopedic care process to another in order to increase the response to the ever-increasing patient demand at this clinic, ${ }^{4}$ specifically in the
Table 3 Simulation results according to scenario

\begin{tabular}{lll}
\hline & $\begin{array}{l}\text { Examination waiting } \\
\text { time (hours) }\end{array}$ & $\begin{array}{l}\text { Throughput } \\
\text { (number of } \\
\text { patients) }\end{array}$ \\
\hline $\begin{array}{l}\text { Base scenario } \\
\text { Base scenario with }\end{array}$ & 2.83 & 5 \\
I-hour increase in & 2.83 & 7.56 \\
operating room and & & \\
I0\% surgery increase & & \\
Scenario I & 1.47 & 9.16 \\
Scenario 2 & 2.83 & 7.56 \\
Scenario 3 & 1.47 & 9.16 \\
Scenario 4 & 1.47 & 9.16 \\
Scenario 5 & 0.77 & 9.71 \\
\hline
\end{tabular}

form of sharing these resources between the orthopedic clinic and operating room. To create flexibility that can increase the speed of response in the operating room, we extended the use of the operating room's capacity by assuming that the surgical process starts 1 hour earlier. Based on discussions with department personnel on current operating room capacity, we further suggested a $10 \%$ increase in daily surgeries. The extended operating room capacity will increase flexibility on this process by allowing surgery process to start earlier than before. This in turn will increase patient throughput at this resource. Several scenarios were developed, as presented in Table 2.

Using simulations, we explored the best resource flexibility scenario and explored its effect on the patient care process. For simulation purposes, we assumed that additional mid-level health workers are involved in the surgeons' treatment process because this proposal has not yet been implemented. That is, data for mid-level health workers care protocol is absent.

From the queuing theory perspective, additional mid-level staff and surgeons are considered as parallel multiple servers and are assumed to have common service time distributions. ${ }^{34}$ Thus, we make the following assumptions: 1) mid-level staff and surgeons maintain the same examination and surgery time distributions; 2) patients enter examination and surgery through common queues based on first-in first-out discipline; 3) the service systems have identical and multiple servers. ${ }^{34,35}$

We know that the current protocol involves orthopedic cases which were treated by surgeons, but since the main focus is to know the impact of these additional resources before actual implementation, we believe that the results based on these assumptions are still relevant for practical decision making.

Patient waiting time is a key indicator of health care accessibility. We thus used this as a benchmark for releasing these resources by assuming that when patient waiting time is less than 2 hours, these resources should be released. 


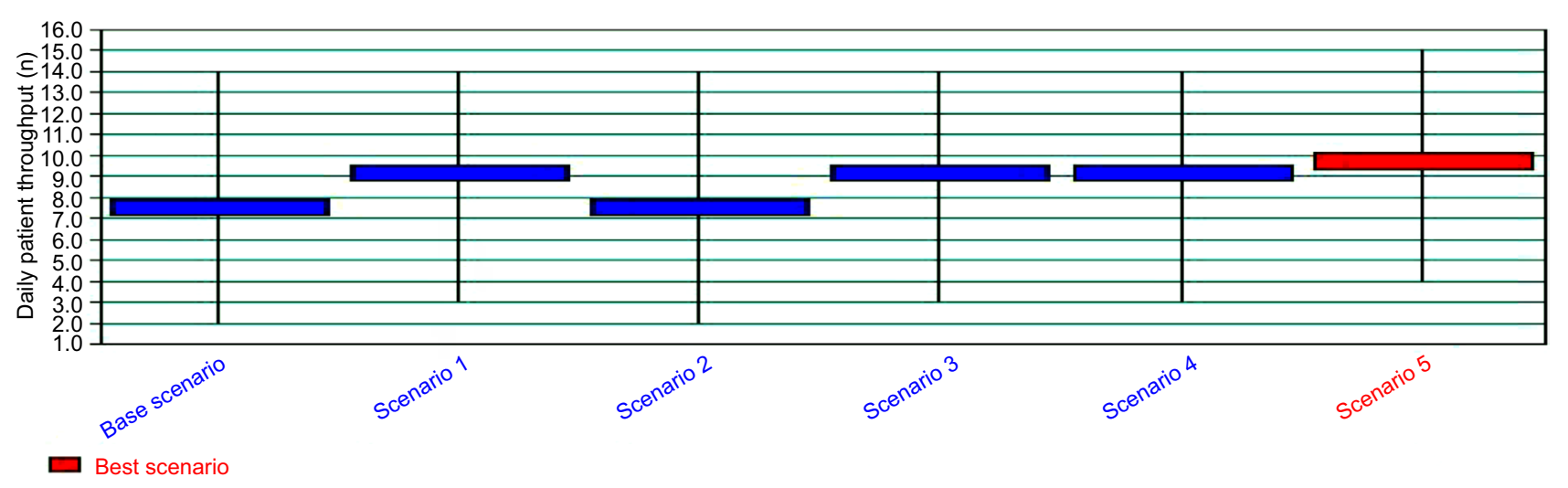

Figure 2 Daily throughput according to scenario.

Note: Black lines represent insignificant scenarios and the significant scenario is represented in red.

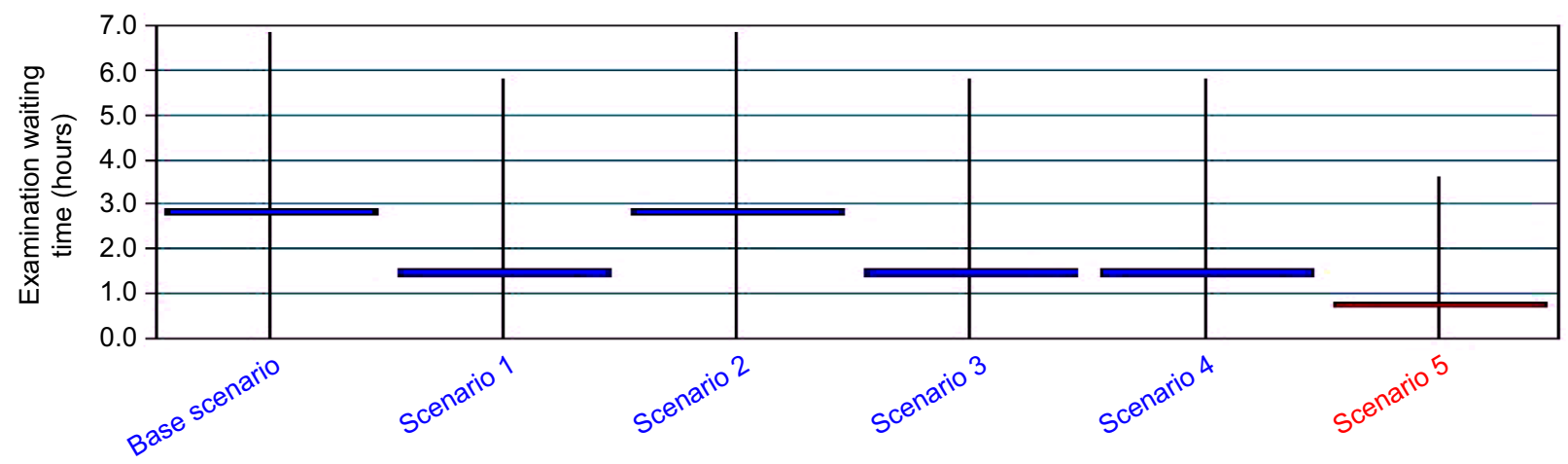

Best scenarıo

Figure 3 Examination queue waiting time according to scenario.

Note: Black lines represent insignificant scenarios and the significant scenario is represented in red.

Table 4 Evaluating process characteristics when demand changes along with corresponding waiting time (hours)

\begin{tabular}{llll}
\hline & $\begin{array}{l}\text { Base scenario } \\
\text { demand } \\
\text { declining by } \\
26.3 \%\end{array}$ & $\begin{array}{l}\text { Best scenario } \\
\text { (scenario 5) }\end{array}$ & $\begin{array}{l}\text { Best scenario } \\
\text { with 84\% } \\
\text { demand } \\
\text { increase }\end{array}$ \\
\hline $\begin{array}{l}\text { Patient } \\
\text { waiting time }\end{array}$ & 2.01 & 0.77 & 1.9 \\
$\begin{array}{l}\text { Throughput } \\
\text { (patients, } \mathbf{n} \text { ) }\end{array}$ & 5 & 9.71 & 14.4 \\
\hline
\end{tabular}

Specifically, we explored the extent to which current demand can decline so that a patient waits a maximum of 2 hours. We further explored to what extent can these additional resources accommodate future increases in demand without patients waiting more than 2 hours.

\section{Results}

\section{Simulation results}

This section presents the simulation results of the orthopedic care process. The simulation model was used to generate the best resource flexibility scenario and to exploring the effect of implementing resource flexibility. It was also used to explore how implementation of resource flexibility affects patient access to healthcare services. Table 3 presents simulation results of the base and six proposed scenarios. The most significant scenario (scenario 5) shows improvements in waiting time by $72.7 \%$ and throughput by $94 \%$.

We used box plots and whisker charts to find statistically significant scenarios at a $95 \%$ confidence interval in patient waiting time and throughput. Figures 2 and 3 present the results, with red indicating a $95 \%$ chance of a best scenario.

The simulation result indicates that if current demand declines by $26.3 \%$ (see Table 4); it can be accommodated with current resources without patients waiting more than 2 hours. These additional resources can thus be used for other clinical purposes. The simulation result further indicates that with this flexibility scenario, up to $84 \%$ of the increase in future demand can be accommodated with patients waiting no longer than 2 hours.

\section{Discussion}

This paper explored how resource flexibility affects patient care process outcome. Specifically, the focus was on 
exploring improvements by deploying resource flexibility in different stages of patient treatment processes. Discrete event simulation was used to run the base scenario that represents orthopedic care process and the proposed six scenarios. The main objective was to ascertain which one is the best scenario. The simulation results indicate that resource flexibility is more beneficial at process stages with bottleneck resources and when processing times are dependent on additional resources. This finding is in line with the literature which demonstrates that resource flexibility is more beneficial in areas with bottlenecks. ${ }^{4}$

The aim of introducing resource flexibility was to increase the speed in responding to orthopedic patient demands on this clinic. The impacts of additional resources on patient waiting time and throughput at this clinic clearly indicate that resource flexibility is a key strategy that can be used to improve healthcare processes. The introduction of a flexible workforce in the model showed improved throughput and a significant reduction in patient waiting time. Improving throughput and decreasing patient waiting time indicate process improvement in terms of increasing response speed to enhance patients' access to care.

We further tested how the best scenario can be used to accommodate future demand. The simulation results demonstrate that with introduction of resource flexibility, this care process would increase rate of response to patient demands. The simulation results show that the improved process can accommodate an increase of up to $84 \%$ in demand without patients waiting more than 2 hours at the clinic. This finding is consistent with the literature asserting that more than $80 \%$ of orthopedic cases are non-surgical. ${ }^{36}$ Thus, increasing resource flexibility at the clinic would be more beneficial to a greater number of patients, given the fact that most cases are non-surgical.

From the perspective of healthcare processes, this study has shown that implementation of agile strategy can lead to improved care processes. The results presented in Table 3 indicate that resource flexibility can reduce patient crowding and waiting time. Introducing resource flexibility created conditions for improved patient flows, decreasing response times in addressing patient needs. In practice, this improvement can be translated into increased patient access to care since the speed of response has increased; more patients can thus be accommodated.

Worldwide, surgeons and operating rooms are the key constraint resources in patient care processes. Creating flexibility in these resources is of great importance in order to improve patient access to care. In this study we have demonstrated on how flexibility in these critical resources can improve healthcare processes. Thus healthcare providers should focus on adopting such innovative ways in order to improve healthcare processes and enhance increased patient access to care.

It is worth noting that, to achieve the intended benefit, implementation of this proposal should be done with a careful analysis of mid-level workforce capacity at the hospital. Two options can be used to obtain additional mid-level health workers in the orthopedic department. First, additional mid-level health workers in the orthopedic department can be taken from departments with more mid-level resources or low service demand, so that service capacity in those departments will not be affected. Second, because training time and cost for mid-level health workers is much lower than specialized surgeons, ${ }^{32}$ hospital providers can still opt to train more mid-level health workers. Training more mid-level health workers will reduce the effect of moving resources from one department to another, eg, some staff may feel overworked.

It should further be noted that additional resource in this proposal has a cost implication, however this proposal is still viable and useful for practical purposes. Recently several studies have suggested that shifting surgical tasks from surgeons to lower level staff (eg, clinical officers, nonphysician clinicians) is an effective response to the shortage of specialized medical staff in resource constrained settings. These studies acknowledged that dedicating tasks to midlevel health workers gives health care providers the ability to deliver health care services to a large number of patients at lower training and labor cost. ${ }^{32,37}$

\section{Managerial implications}

This study provides significant contribution to healthcare providers regarding the benefit of resource flexibility in patient care processes.

First, the simulation results suggest that the deployment of resource flexibility can increase the speed of responding to patient demand, leading to reduced crowding in clinics. Health care providers should thus consider the possibility of using mid-level resources in orthopedic fields. The fact that mid-level health workers have already performed major surgery in other surgical fields (Beard et al and Gupta et al) ${ }^{32,37}$ might be a good indicator that they can manage simple cases at the orthopedic level.

Second, the simulation results of this study have a major implication for healthcare providers aiming to improve healthcare processes. To meet increasing patient demand as well as reducing patient delays in care processes, healthcare managers should start focusing on introducing flexibility in 
different parts of care processes. Retaining resources that can be shifted during different stages of the healthcare production process can increase the speed of responding to patient needs and demands at the various stages of their treatment.

\section{Conclusion}

The results of this study indicate that if this scenario is to be implemented, it can potentially improve patient access to care and thereby contribute to reducing morbidity and mortality in orthopedic surgical cases. This paper focuses on showing the advantage of an agile strategy in the improvement of healthcare processes, particularly in resource-constraint settings. With the result of simulation modeling on the impact of resource flexibility, we point out that an agile strategy can improve healthcare processes as well as patient access to healthcare.

This study faces some limitations. First, patient waiting time includes the early arrival of patients before the start of examination services as well as surgeons lateness. If surgeons could arrive at the start of clinic session patient waiting time could be decreased. Likewise, if patients could arrive a few minutes before the start of the clinical session, this could further decrease their waiting time.

Second, our model was limited to orthopedic treatment processes. Future research can focus on exploring more care processes and evaluating how efficiently proposed flexible workforce can perform multiple tasks between several clinics as well as the trade-offs involved when trying to introduce flexible workforce in multiple care processes.

Lastly, observational data for additional mid-level health workers are missing, thus our simulation result is based on the collected surgeons' service time data. After implementation the result may be slightly different because mid-level health workers will have their own protocol, ie, dealing with minor and routine orthopedic cases. However, the impact of reduced waiting time and improved patient access to care will still be relevant. This is because the workload will be distributed between mid-level staff and surgeons. Hence, surgeon capacity will be freed up and they can focus on more complex cases. Nevertheless, this limitation calls for further research to investigate the impact of additional mid-level staff after implementation of this proposal.

\section{Acknowledgments}

The authors would like to thank the management of Bugando Hospital for allowing us to collect data for this study. We would also like to thank all health care providers for their great help during the data collection period. The authors would further like to express great thanks to associate professor Ketil Danielsen of Molde University College for comments on the simulation part.

\section{Disclosure}

The authors report no conflicts of interest in this work.

\section{References}

1. Ford WE, Scanlon PD. Promise and problems with supply chain management approaches to healthcare purchasing. Health Care Manage Rev. 2007;32(3):192-202.

2. Tolf S, Nyström ME, Tishelman C, Brommels M, Hansson J. Agile, a guiding principle for health care improvement? Int J Health Care Qual Assur. 2015;28(5):468-493.

3. Vissers JM, Bertrand JW, De Vries G. A framework for production control in health care organizations. Production Planning and Control. 2001;12(6):591-604.

4. Daniels RL, Mazzola JB, Shi D. Flow Shop Scheduling with Partial Resource Flexibility. Manage Sci. 2004;50(5):658-669.

5. Aronsson H, Abrahamsson M, Spens K. Developing lean and agile health care supply chains. Supply Chain Management. 2011;16(3):176-183.

6. Lillrank P, Groop J, Venesmaa J. Processes, episodes and events in health service supply chains. Supply Chain Management. 2011;16(3):194-201.

7. Olsson O, Aronsson H. Managing a variable acute patient flow: categorising the strategies. Supply Chain Management. 2015;20(2):113-127.

8. Vries J De, Huijsman R. Supply chain management in health services: an overview. Supply Chain Management. 2011;16(3):159-165.

9. Christopher M. The agile supply chain competing in volatile markets. Ind Mark Manag. 2000;44:37-44.

10. Rahimnia F, Moghadasian M. Supply chain leagility in professional services: how to apply decoupling point concept in healthcare delivery system. Supply Chain Management: An International Journal. 2010;15(1):80-91.

11. Mclaughlin D, Hays JM. Healthcare Operations Management. 1st ed. Washington, DC: Foundation of the American College of Healthcare Executives; 2008.

12. Pati D, Harvey T, Cason C. Inpatient unit flexibility: design characteristics of a successful flexible unit. Environ Behav. 2008;40(2):205-232

13. Olsson NEO, Hansen GK. Identification of critical factors affecting flexibility in hospital construction projects. HERD. 2010;3(2):30-47.

14. Ramesh G, Devadasan SR. Literature review on the agile manufacturing criteria. J Manuf Technol Manag. 2007;18(2):182-201.

15. Ismail HS, Sharifi H. A balanced approach to building agile supply chains. Int J Phys Distrib Logist Manag. 2006;36(6):431-444.

16. Swafford PM, Ghosh S, Murthy N. The antecedents of supply chain agility of a firm: Scale development and model testing. J Oper Manag. 2006;24(2):170-188.

17. van Hoek RI, Harrison A, Christopher M. Measuring agile capabilities in the supply chain. Int J Oper Prod Manag. 2001;21(1/2):126-148.

18. Daniels RL, Mazzola JB, Shi D. Flow shop scheduling with resource flexibility. Manage Sci. 1993;50(5):658-669.

19. Farrar J, AbouRizk S, Mao X. Generic implementation of lean concepts in simulation models. Lean Constr J. 2004;1(October 2004):1-23.

20. Sharma V, Abel J, Al-Hussein M, Lennerts K, Pfründer U. Simulation application for resource allocation in facility management processes in hospitals. Facilities. 2007;25(13/14):493-506.

21. Barjis J. Healthcare simulation potentials and challenges. Simulation. 2010;86(8-9):459-462.

22. Weerawat W, Pichitlamken J, Subsombat P. A generic discrete-event simulation model for outpatient clinics in a large public hospital. J Healthc Eng. 2013;4(2):285-305.

23. Rau CL, Tsai PF, Liang SF, et al. Using discrete-event simulation in strategic capacity planning for an outpatient physical therapy service. Health Care Manag Sci. 2013;16(4):352-365. 
24. Baril C, Gascon V, Cartier S. Design and analysis of an outpatient orthopaedic clinic performance with discrete event simulation and design of experiments. Comput Ind Eng. 2014;78:285-298.

25. Duguay C, Chetouane F. Modeling and improving emergency department systems using discrete event simulation. Simulation. 2007;83(4):311-320.

26. World Health Organization [reviewed September 2016]. Road traffic injuries. Available from: http://www.who.int/mediacentre/factsheets/ fs358/en/. Accessed September 9, 2016.

27. Chalya PL, Dass RM, McHembe MD, et al. Citywide trauma experience in Mwanza, Tanzania: a need for urgent intervention. J Trauma Manag Outcomes. 2013;7(1):9.

28. Law AM, Kelton WD. Simulation Modeling and Analysis. 3rd ed. New York, NY: McGraw Hill; 2000.

29. Venkatadri V, Raghavan VA, Kesavakumaran V, Lam SS, Srihari K. Simulation based alternatives for overall process improvement at the cardiac catheterization lab. Simul Model Pract Theory. 2011;19(7): 1544-1557.

30. Ruohonen T, Neittaanmäki P, Teittinen J. Simulation model for improving the operation of the emergency department of special health care: Proceedings of the 38th Winter simulation conference. IEEE: Computer Society; 2006:453-458.
31. Global Health Workforce Alliance. Mid-level Health Workers for Delivery of Essential Health Services. Geneva: World Health Organization; 2013. Available from: http://www.who.int/workforcealliance/knowledge/ resources/mlp2013/en/. Accessed September 25, 2016.

32. Beard JH, Oresanya LB, Akoko L, Mwanga A, Mkony CA, Dicker RA. Surgical task-shifting in a low-resource setting: outcomes after major surgery performed by nonphysician clinicians in Tanzania. World $J$ Surg. 2014;38(6):1398-1404.

33. Mid-level health workers for delivery of essential health services: Annex 5. Tanzania. World Health Organization; 2013. Available from: http:// www.who.int/workforcealliance/knowledge/resources/MLHWCountryCaseStudies_annex5_Tanzania.pdf?ua=1. Accessed February 22, 2016.

34. Altiok T, Melamed B. Simulation Modeling and Analysis with Arena. 1st Ed. Elsevier Inc. Boston; 2007.

35. Kim SC, Horowitz I, Young KK, Buckley TA. Analysis of capacity management of the intensive care unit in a hospital. Eur J Oper Res. 1999;115(1):36-46.

36. Meer RB van der, Rymaszewski LA, Findlay H, Curran J. Using OR to support the development of an integrated Musculo-Skeletal service. J Oper Res Soc. 2005;56(2):162-172.

37. Gupta B, Huckman RS, Khanna T. Task shifting in surgery: Lessons from an Indian Heart Hospital. Healthcare. 2015;3(4):245-250.
Journal of Multidisciplinary Healthcare

\section{Publish your work in this journal}

The Journal of Multidisciplinary Healthcare is an international, peerreviewed open-access journal that aims to represent and publish research in healthcare areas delivered by practitioners of different disciplines. This includes studies and reviews conducted by multidisciplinary teams as well as research which evaluates the results or conduct of such teams or health
Dovepress

care processes in general. The journal covers a very wide range of areas and welcomes submissions from practitioners at all levels, from all over the world. The manuscript management system is completely online and includes a very quick and fair peer-review system. Visit http://www.dovepress.com/ testimonials.php to read real quotes from published authors. 